
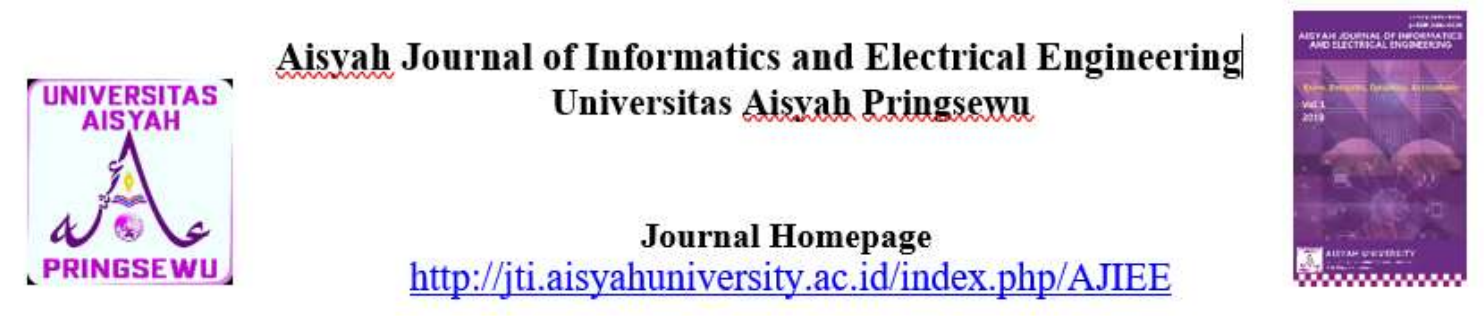

\title{
SISTEM PENDUKUNG KEPUTUSAN DALAM \\ PEMILIHAN SISWA BERPRESTASI DENGAN MENGGUNAKAN METODE AHP DAN TOPSIS
}

\author{
Tahta Herdian Andika ${ }^{1}$, Nurul Isti Fada ${ }^{2}$ \\ ${ }^{1,2}$ Program Studi Teknik Informatika, Fakultas Teknologi dan Informatika \\ Universitas Aisyah Pringsewu \\ e-mail: tahta.herdian.a@gmail.com
}

\begin{abstract}
Abstrak
Pemilihan siswa berprestasi menjadi sesuatu yang penting selain untuk lebih meningkatkan motivasi siswa yang juga agar mendapatkan bibit unggul yang akan dibina agar lebih berprestasi lagi. Saat ini pemilihan siswa berprestasi dilakukan manual dan melalui hasil raport saja. Penilaian dengan jumlah siswa yang banyak sangat menyulitkan pihak sekolah, hasil penilaian dan pertimbangan pengambilan keputusan cenderung lebih subjektif, sehingga cenderung terjadi kesalahan dalam pengambilan keputusan akhir siswa mana yang berprestasi. Oleh karena itu Diperlukan sistem pendukung keputusan yang akan memudahkan pemilihan siswa berprestasi dan membuat keputusan yang efektif dan efisien. AHP dan TOPSIS merupakan metode yang akan digunakan dalam memberikan rekomendasi kepada siswa yang berprestasi sesuai dengan yang diharapkan. Sistem pendukung keputusan ini merupakan alat bantu yang dapat memberikan solusi dalam proses pemilihan siswa berprestasi secara komputerisasi agar lebih efektif dan efisien serta tepat dan akurat. Hasil penelitian membuktikan bahwa aplikasi ini mampu membantu madrasah dalam proses seleksi pemilihan siswa berprestasi dengan metode AHP yang lebih baik dari metode TOPSIS.
\end{abstract}

Kata kunci: Prestasi, SPK, AHP, TOPSIS 


\section{Pendahuluan}

Strategi pendidikan yang ditempuh selama ini bersifat umum, memberikan perlakuan standar atau rata-rata kepada semua siswa, sehingga kurang memperhatikan perbedaan antar siswa dalam kecakapan, minat, dan bakatnya. Dengan strategi semacam ini, keunggulan akan muncul secara acak dan sangat tergantung kepada motivasi belajar siswa serta lingkungan belajarnya. Oleh karena itu, perlu dikembangkan keunggulan yang dimiliki oleh setiap siswa agar potensi yang dimiliki dapat dikonversi menjadi prestasi yang unggul. Pemilihan siswa berprestasi di setiap sekolah pada umumnya berdasarkan nilai raport.

Siswa yang menduduki peringkat 1 sampai 3 tingkat sekolah akan dianggap sebagai siswa berprestasi dan mendapatkan beasiswa. Saat ini pihak sekolah masih menggunakan cara manual dalam menentukan siswa berprestasi tersebut. Penilaian dengan jumlah siswa yang banyak akan menyulitkan pihak sekolah, hasil penilaian dan pertimbangan pengambilan keputusan cenderung subjektif, sehingga cenderung terjadi kesalahpahaman dalam pengambilan keputusan akhir siswa mana yang menjadi siswa berprestasi.

Sistem pendukung keputusan merupakan suatu sistem berbasis komputer, yang dapat mendukung pengambilan keputusan untuk menyelesaikan masalah yang semi terstruktur [1], dengan memanfaatkan data yang ada kemudian diolah menjadi suatu informasi berupa usulan menuju suatu kepuusan tertentu. Sistem Pendukung Keputusan (SPK) dengan metode Analitical Hierarchy Process (AHP) dan Technique For Order Preference by Similarity to Ideal Solution (TOPSIS) merupakan salah satu solusi untuk memfasilitasi pihak sekolah dalam memilih siswa yang layak menjadi siswa berprestasi. Pada Sistem Pendukung Keputusan terdapat prosedur yang harus diikuti dan kriteria untuk masing-masing prosedur bersifat jelas dan kuantitatif sehingga keputusan yang diambil lebih sistematis [2]. Oleh karena itu dibutuhkan suatu sistem pendukung keputusan yang dapat memberikan solusi yang dapat membantu dalam proses pemilihan siswa berprestasi secara komputerisasi agar lebih efektif dan efisien serta tepat dan akurat dan memudahkan para guru ataupun staf untuk memilih siswa yang pantas untuk menjadi siswa berprestasi.

\section{Tinjauan Pustaka}

\subsection{Metode Pengembangan Sistem}

Metode pengembangan sistem yang digunakan adalah System Development Live Cycle (SDLC) dengan pendekatan model Waterfall. Model ini bersifat sistematis dan urut dalam membangun sebuah sistem.

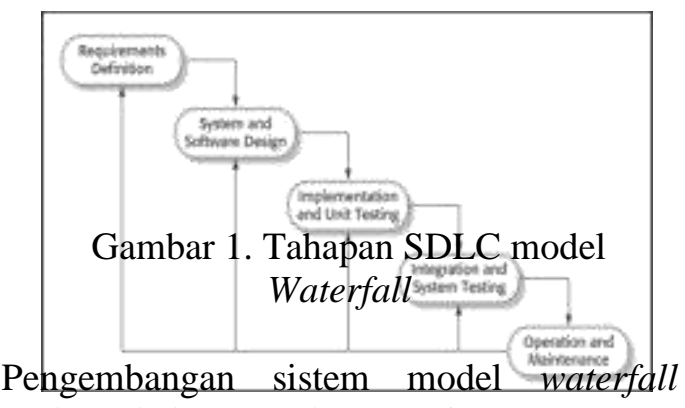
terdapat beberapa tahapan yaitu [3]:

1) mendefinisi kebutuhan

2) merancangan sistem dan perangkat lunak

3) implementasi dan pengujian unit

4) integrasi dan pengujian sistem

5) operasi dan pemeliharaan/maintenance

\subsection{Algoritma Analitical Hierarchy Process (AHP)}

Dalam metode AHP dilakukan langkahlangkah sebagai berikut [4]:

a. Mendefinisikan masalah dan menentukan solusi yang diinginkan.

b. Membuat struktur hierarki yang diawali dengan tujuan utama.

c. Membuat matrik perbandingan berpasangan yang menggambarkan kontribusi relatif atau pengaruh 
setiap elemen terhadap tujuan atau kriteria yang setingkat di atasnya

d. MelakukanMendefinisikanperbandi ngan berpasangan sehingga diperoleh jumlah penilaian seluruhnya sebanyak $\mathrm{n}$. $\mathrm{n}$ adalah banyaknya elemen.

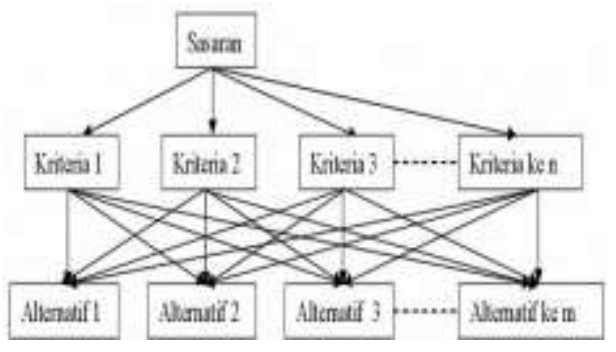

Gambar 2 Contoh Struktur Hierarki AHP

\subsection{Algoritma Technique For Order Preference by Similarity to Ideal Solution (TOPSIS)}

Langkah-langkah yang harus dilakukan untuk memperoleh hasil penilaian dalam metode TOPSIS adalah :

Membangun normalized decision matrix [5] Elemen rij hasil dari normalisasi decision matrix R dengan metode Euclidean length of a vector adalah:

$$
r_{v}-\frac{x_{v i}}{\sqrt{\sum_{t=1}^{m} \cdot x_{i t}^{2}}}
$$

Membangun weighted normalized decision matrix Dengan bobot $\mathrm{W}=(\mathrm{w} 1, \mathrm{w} 2, \ldots \ldots, \mathrm{wn})$, maka normalisasi bobot matriks $\mathrm{V}$ adalah:

$$
\mathrm{V}=\left[\begin{array}{cccc}
w_{1} r_{11} & w_{2} r_{12} & \ldots & w_{n} r_{1 n} \\
w_{1} r_{21} & & & \\
w_{12} m_{1} & w_{2} r_{m 2} & \ldots & w_{n} r_{\mathrm{men}}
\end{array}\right]
$$

Menentukan solusi ideal dan solusi ideal negatif.

Solusi ideal dinotasikan A*, sedangkan solusi ideal negatif dinotasikan A- :

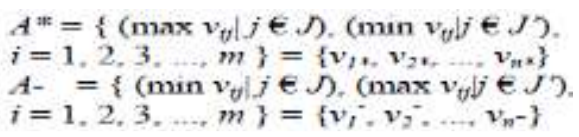

Dimana:

$\mathrm{J}=\{\mathrm{j}=1,2,3, \ldots, \mathrm{n}$ dan $\mathrm{j}$ merupakan benefit criteria $\}$ $\mathrm{J}^{\prime}=\{\mathrm{j}=1,2,3, \ldots, \mathrm{n}$ dan $\mathrm{j}$ merupakan cost criteria $\}$
Menghitung separasi $\mathrm{Si}^{*}$ adalah jarak (dalam pandangan Euclidean) alternatif dari solusi idealdidefinisikan sebagai:

$$
S_{i,}-\sqrt{\sum_{f=1}^{n}\left(v_{v}-v_{j}^{*}\right)^{2}} \text {, dengan } i-1,2,3, \ldots, m
$$

Dan jarak terhadap solusi negatif-ideal didefinisikan sebagai:

$$
S_{i^{-}}=\sqrt{\sum_{j=1}^{n}\left(v_{i j}-v_{j}^{-}\right)^{2}} \text {, dengan } i=1,2,3, \ldots, m
$$

Menghitung kedekat an relatif terhadap solusi ideal

$$
C_{i^{*}}=\frac{S_{i^{-}}}{S_{i^{*}}+S_{i^{-}}} \text {, dengan } 0<C_{i^{*}}<1 \text { dan } i=1,2,3, \ldots, m
$$

\section{METODOLOGI}

\subsection{Jenis Penelitian}

Penelitian ini bersifat deskriptif kuantitatif. Deskriptif adalah desain riset yang lebih menekankan pada penentuan frekuensi terjadinya sesuatu atau sejauh mana suatu variabel saling berhubungan, merupakan penelitian yang bisa menggambarkan karakteristik dari obyek, manusia, kelompok, organisasi maupun lingkungan dengan kata lain penelitian ini harus bisa menggambarkan yang berkenaan dengan apa, siapa, dimana dan bagaimana.

\subsection{Analisis kebutuhan}

Penentuan pemilihan siswa berprestasi dengan menggunakan Analytical Hierarchy Process dan topsis akan berfungsi sebagai sarana untuk mempercepat pengambilan keputusan di lingkungan manajemen MI AlHuda Wargomulyo. Untuk melakukan pemilihan siswa berprestasi diperlukan suatu 
analisis kebutuhan, guna membantu dalam melakukan kegiatan analisis data, analisis proses dan analisis kuisioner komponen AHP dan TOPSIS

\subsection{Teknik Pengumpulan Data}

Berdasarkan sumbernya, data penelitian dapat dikelompokkan menjadi dua jenis yaitu data primer dan data sekunder.

1. Data Primer adalah data yang diperoleh atau dikumpulkan oleh peneliti secara langsung dari sumber datanya. Data primer disebut juga sebagai data asli atau data terbaru. Untuk mendapatkan data primer, peneliti harus mengumpulkannya secara langsung.

Teknik yang dapat digunakan peneliti untuk mengumpulkan data primer antara lain observasi, wawancara, diskusi terfokus.

2. Data Sekunder adalah data yang diperoleh atau dikumpulkan peneliti dari berbagai sumber yang telah ada. Data sekunder dapat diperoleh dari berbagai sumber seperti nilai raport, buku, tugas, laporan dan arsip lainnya yang dapat dijadikan penilaian panitia.

\section{Hasil dan Pembahasan \\ 4.1 Membuat Matriks Berpasangan AHP}

Untuk setiap kriteria dan alternatif, kita harus melakukan perbandingan berpasangan (pairwaisecomparison) yaitu membandingkan setiap elemen dengan elemen lainnya pada setiap tingkat hirarki secara berpasangan sehingga didapat nilai tingkat kepentingan elemen dalam bentuk pendapat kualitatif.

Tabel 5. Matrik Perbandingan Pasangan

\begin{tabular}{|l|c|c|c|c|}
\hline \multicolumn{1}{|c|}{ Kriteria } & $\begin{array}{c}\text { Tingkah } \\
\text { Laku }\end{array}$ & Akademik & Absensi & Raport \\
\hline $\begin{array}{l}\text { Tingkah } \\
\text { Laku }\end{array}$ & 1 & 5 & $1 / 3$ & $1 / 4$ \\
\hline Akademik & $1 / 5$ & 1 & $1 / 7$ & $1 / 8$ \\
\hline Absensi & 3 & 7 & 1 & $1 / 2$ \\
\hline Raport & 4 & 8 & 2 & 1 \\
\hline Jumlah & 8.2 & 21 & 3.476 & 1.875 \\
\hline
\end{tabular}

Tabel 6. Hasil Pembagian Matrik Perbandingan Berpasangan

Tabel 7. Matrik Kriteria dan Prioritas

\begin{tabular}{|l|c|c|c|c|c|c|}
\hline $\begin{array}{l}\text { Kriter } \\
\text { ia }\end{array}$ & $\begin{array}{c}\text { Ting } \\
\text { kah } \\
\text { Lak } \\
\mathrm{u}\end{array}$ & $\begin{array}{c}\text { Akad } \\
\text { emik }\end{array}$ & $\begin{array}{c}\text { Abs } \\
\text { ensi }\end{array}$ & $\begin{array}{c}\text { Rap } \\
\text { ort }\end{array}$ & $\begin{array}{c}\text { Jum } \\
\text { lah }\end{array}$ & $\begin{array}{c}\text { bob } \\
\text { ot }\end{array}$ \\
\hline $\begin{array}{l}\text { Tingk } \\
\text { ah } \\
\text { Laku }\end{array}$ & $\begin{array}{c}0.12 \\
195\end{array}$ & $\begin{array}{c}0.238 \\
09\end{array}$ & $\begin{array}{c}0.09 \\
589\end{array}$ & $\begin{array}{c}0.13 \\
333\end{array}$ & $\begin{array}{c}0.58 \\
92\end{array}$ & $\begin{array}{c}0.14 \\
731\end{array}$ \\
\hline $\begin{array}{l}\text { Akad } \\
\text { emik }\end{array}$ & $\begin{array}{c}0.02 \\
439\end{array}$ & $\begin{array}{c}0.047 \\
6\end{array}$ & $\begin{array}{c}0.04 \\
109\end{array}$ & $\begin{array}{c}0.06 \\
666\end{array}$ & $\begin{array}{c}0.17 \\
97\end{array}$ & $\begin{array}{c}0.04 \\
494\end{array}$ \\
\hline $\begin{array}{l}\text { Abse } \\
\text { nsi }\end{array}$ & 0.36 & $\begin{array}{c}0.333 \\
385\end{array}$ & $\begin{array}{c}0.28 \\
768\end{array}$ & $\begin{array}{c}0.26 \\
666\end{array}$ & $\begin{array}{c}1.25 \\
35\end{array}$ & $\begin{array}{c}0.31 \\
338\end{array}$ \\
\hline $\begin{array}{l}\text { Rapor } \\
\mathrm{t}\end{array}$ & 0.48 & 0.380 & 0.57 & 0.53 & 1.97 & 0.49 \\
780 & 9 & 537 & 333 & 74 & 436 \\
\hline $\begin{array}{l}\text { Jumla } \\
\text { h }\end{array}$ & 1 & 1 & $\begin{array}{c}1.00 \\
005\end{array}$ & 1 & $\begin{array}{c}4.00 \\
00\end{array}$ & $\begin{array}{c}1.00 \\
001\end{array}$ \\
\hline
\end{tabular}


Tabel 8. Matrik perbandingan berpasangan nilai raport

Tabel 9. matrik perbandingan berpasangan

\begin{tabular}{|l|c|c|c|c|}
\hline Kriteria & $\begin{array}{c}\text { Tingka } \\
\text { h Laku }\end{array}$ & $\begin{array}{c}\text { Aka } \\
\text { demi } \\
\mathrm{k}\end{array}$ & $\begin{array}{c}\text { Absen } \\
\text { si }\end{array}$ & $\begin{array}{c}\text { Ra } \\
\text { po } \\
\text { rt }\end{array}$ \\
\hline $\begin{array}{l}\text { Tingka } \\
\text { h Laku }\end{array}$ & 1 & 5 & $\begin{array}{c}0.3333 \\
33333\end{array}$ & $\begin{array}{c}0.2 \\
5\end{array}$ \\
\hline $\begin{array}{l}\text { Akade } \\
\text { mik }\end{array}$ & 0.2 & 1 & $\begin{array}{c}0.1428 \\
57143\end{array}$ & $\begin{array}{c}0.1 \\
25\end{array}$ \\
\hline $\begin{array}{l}\text { Absens } \\
\text { i }\end{array}$ & 3 & 7 & 1 & 0.5 \\
\hline Raport & 4 & 8 & 2 & 1 \\
\hline Jumlah & 8.2 & 21 & $\begin{array}{c}3.4761 \\
90476\end{array}$ & $\begin{array}{c}1.8 \\
75\end{array}$ \\
\hline
\end{tabular}

Absensi
4.2

\begin{tabular}{|c|c|c|c|}
\hline Kriteria & B & C & K \\
\hline B & 1 & 2 & 6 \\
\hline C & 0.5 & 1 & 2 \\
\hline K & 0.17 & 0.5 & 1 \\
\hline Jumlah & 1.67 & 3.5 & 9 \\
\hline
\end{tabular}

Membuat Matriks TOPSIS

Pengujian metode topsis dilakukan dengan melakukan perhitungan berdasarkan bobot yang telah dibuat sebelumnya.

Tabel 11. Data kriteria

\begin{tabular}{|c|c|c|c|}
\hline Kriteria & B & C & K \\
\hline B & 1 & 3 & 4 \\
\hline C & 0.33 & 1 & 3 \\
\hline K & 0.25 & 0.33 & 1 \\
\hline Jumlah & 1.58 & 4.33 & 8 \\
\hline
\end{tabular}

Tabel 12. Tabel Perbandingan Hasil

\begin{tabular}{|c|c|c|c|}
\hline $\begin{array}{c}\text { Meto } \\
\text { de }\end{array}$ & $\begin{array}{c}\text { Rangki } \\
\text { ng } 1\end{array}$ & $\begin{array}{c}\text { Rangkin } \\
\text { g } 2 \\
\end{array}$ & $\begin{array}{c}\text { Rangkin } \\
\text { g 3 } \\
\end{array}$ \\
\hline $\begin{array}{c}\text { Perse } \\
\text { psi } \\
\text { Guru }\end{array}$ & $\begin{array}{l}\text { Darin } \\
\text { Fairuz }\end{array}$ & $\begin{array}{c}\text { Afifah } \\
\text { Khoirunn } \\
\text { isa }\end{array}$ & $\begin{array}{c}\text { Naufal } \\
\text { Dafa } \\
\text { Mifdlal }\end{array}$ \\
\hline $\begin{array}{c}\text { Metod } \\
\text { e } \\
\text { AHP }\end{array}$ & $\begin{array}{l}\text { Darin } \\
\text { Fairuz }\end{array}$ & $\begin{array}{c}\text { Afifah } \\
\text { Khoirunn } \\
\text { isa }\end{array}$ & $\begin{array}{c}\text { Naufal } \\
\text { Dafa } \\
\text { Mifdlal }\end{array}$ \\
\hline $\begin{array}{c}\text { Metod } \\
\mathrm{e} \\
\text { TOPS } \\
\text { IS }\end{array}$ & $\begin{array}{c}\text { Darin } \\
\text { Fairuz } \\
\text { / Naufal } \\
\text { Dafa } \\
\text { Mifdlal }\end{array}$ & $\begin{array}{c}\text { Darin } \\
\text { Fairuz / } \\
\text { Naufal } \\
\text { Dafa } \\
\text { Mifdlal }\end{array}$ & $\begin{array}{c}\text { Afifah } \\
\text { Khoirunn } \\
\text { isa }\end{array}$ \\
\hline
\end{tabular}

Dari hasil perbandingan tabel 12 diperoleh hasil perbandingan perhitungan metode AHP dan persepsi guru dengan hasil yang sama akan tetapi persepsi guru di anggap kurang obyektif dikarenakan ada beberapa faktor yang dapat mempengaruhi hasil dari pemilihan siswa berprestasi tersebut. Faktor yang dapat mempengaruhi hasil siswa berprestasi tersebut diantaranya : 
1. Guru mempunyai kedekatan terhadap salah satu siswa

2. Guru masih ada ikatan keluarga dengan siswa

3. Guru hanya melihat faktor akademik sedangkan dengan menggunakan metode ada 4 kriteria yang harus terpenuhi.

\section{Simpulan}

Berdasarkan penelitian yang sudah dilakukan dapat diambil kesimpulan bahwa Analytic Hierarchy Process (AHP) mempunyai kemampuan untuk memecahkan masalah yang multi obyektif dan multi kriteria yang berdasarkan pada perbandingan preferensi dari setiap elemen dalam hirarki. Sehingga dapat dikatakan bahwa nalytic Hierarchy Process (AHP) merupakan suatu metode pengambilan keputusan yang komprehensif. sedangkan dengan menggunakan metode TOPSIS diproleh hasil untuk Rangking 1 dan rangking 2 sama sehingga belum mampu atau kurang akurat untuk menentukan rangking 1 dan rangking 2. Hal ini menunjukan metode topsis kurang baik jika digunakan dalam mendapatkan bobot yang memperhitungkan hubungan antara kriteria. Jadi dengan digunakannya system pendukung keputusan dengan menggunakan metode AHP dan TOPSIS ini diharapkan dapat mencegah adanya pemilihan siswa berprestasi yang tidak obyektif.

\section{Daftar Pustaka}

[1] Kusrini. 2007. Konsep dan Aplikasi Sistem Pendukung

Keputusan.Yogyakarta : ANDI

[2] Hafiz, A., \& Ma'mur, M. 2018. Sistem Pendukung Keputusan Pemilihan Karyawan Terbaik Dengan Pendekatan Weighted Product. Jurnal Cendikia, 15(1 April), 23-28.

[3] Rizki Alfiasca, Pantjawati, Sudarmaningtyas. 2014. Rancang Bangun Sistem Informasi Manajemen Arsip Rumah Sakit Bedah Surabaya Berbasis Web. JSIKA Vol 3, No 1. STMIK STIKOM Surabaya.

[4] Ambrowati, Armadiyah,

"SistemPendukung Keputusan Pemilihan Karyawan Berprestasi Berdasarkan Kinerja dengan Metode AHP" dalam Seminar Nasional Aplikasi Teknologi Informasi (SNATI 2007). Jogjakarta : Jurusan Teknik Informatika Universitas Islam Indonesia, 2006.

[5] Rika yunitarini. TOPSIS (Technique For Others Reference by Similarity to Ideal Slution). www. liyantanto.files.wordpress.com/2009/0 9/ahp-dan-topsis1.ppt. Diakses tanggal 2 Maret, 2010 